\title{
Inovasi teknologi hidroponik melalui pemanfaatan barang bekas dan nutrisi buatan sendiri sebagai usaha peningkatan pendapatan petani di Desa Kualu Kecamatan Tambang Kabupaten Kampar
}

\author{
Fitmawati $^{* 1}$, Mayta Novaliza Isda ${ }^{1}$, Isnaini ${ }^{2}$, Nery Sofiyanti ${ }^{1}$, \& Rodesia Mustika Roza ${ }^{1}$ \\ ${ }^{1}$ Jurusan Biologi, Fakultas Matematika dan Ilmu Pengetahuan Alam, Universitas Riau \\ ${ }^{2}$ Jurusan Agroteknologi, Fakultas Pertanian, Universitas Riau \\ * fitmawati@ lecturer.unri.ac.id
}

\begin{abstract}
Abstrak. Teknologi hidroponik sistem wick adalah salah satu inovasi budidaya sayur-mayur tanpa tanah dengan inovasi pemanfaataan barang bekas dan sampah rumah tangga seperti styrofoam dan kaleng bekas sebagai wadah penanaman. Tujuan kegiatan ini adalah untuk mengurangi sampah di lingkungan masyarakat, meningkatkan kemampuan ekonomi keluarga, dan minat masyarakat mengkonsumsi sayuran yang bersih dan higienis di Desa Kualu Kecamatan Tambang Kabupaten Kampar. Teknik hidroponik ini terbuat dari bahan relatif murah dan terjangkau, sehingga keterbatasan kemampuan finansial masyarakat dapat teratasi. Sistem ini merupakan sistem hidroponik yang menggunakan sumbu untuk menyerap nutrisi organik. Untuk meminimalisir biaya pembelian nutrisi dapat diatasi dengan inovasi larutan hara dari sampah buangan rumah tangga menjadi pupuk cair. Pelaksanaan pengabdian kepada masyarakat ini menggunakan metode penyuluhan, diskusi dan pembuatan teknologi hidroponik. Masyarakat sangat antusias mengikuti program ini, terutama ibu rumah tangga yang ingin mengetahui pengaplikasian teknologi hidroponik Sistem Wick, sehingga dapat berperan besar dalam memenuhi kebutuhan pangan dan meningkatkan pendapatan masyarakat.
\end{abstract}

Kata kunci: hidroponik; sampah; sayur-mayur; sistem wick

\begin{abstract}
The hydroponic technology of the wick system is one of the innovations in vegetable cultivation without soil with the innovation of utilizing used goods and household waste such as styrofoam and used cans as a container for planting. The purpose of this activity is to reduce waste in the community, improve the family's economic capacity, and people's interest in consuming clean and hygienic vegetables in Kualu Village, Tambang District, Kampar Regency. This hydroponic technique is made of relatively inexpensive and affordable materials, so that the limitations of people's financial capabilities can be overcome. This system is a hydroponic system that uses axes to absorb organic nutrients. To minimize the cost of purchasing nutrients, it can be overcome by innovating nutrient solutions from household waste into liquid fertilizer. The implementation of community service uses counseling, discussion and making hydroponic technology. The community is very enthusiastic in joining this program, especially housewives who want to know the application of Wick's hydroponic technology, so that they can play a large role in meeting food needs and increasing people's income.
\end{abstract}

Keywords: hydroponics; garbage; vegetables; wick systems

To cite this article: Fitmawati, M. N. Isda, Isnaini, N. Sofiyanti, R. M. Roza. 2019. Inovasi teknologi hidroponik melalui pemanfaatan barang bekas dan nutrisi buatan sendiri sebagai usaha peningkatan pendapatan petani di Desa Kualu Kecamatan Tambang Kabupaten Kampar. Unri Conference Series: Community Engagement 1: 499-505 https://doi.org/10.31258/unricsce.1.499-505

(C) 2019 Authors

Peer-review under responsibility of the organizing committee of Seminar Nasional Pemberdayaan Masyarakat 2019 


\section{PENDAHULUAN}

Sayuran adalah tanaman hortikultura yang menjadi salah satu pangan primer bagi keberlangsungan hidup manusia. Varietas tanaman musiman ini mempunyai warna, rasa, aroma dan tekstur yang berbeda-beda sehingga sebagai bahan pangan sayuran dapat menambah variasi makanan. Menurut Kemenskes RI (2014), sayuran sebagai salah satu sumber mineral dan vitamin yang memegang peranan penting dalam pemenuhan kebutuhan pangan dan peningkatan gizi masyarakat. Komoditas hortikultura khususnya sayuran dan buahbuahan memegang bagian terpenting dari keseimbangan pangan, sehingga harus tersedia setiap saat dalam jumlah yang cukup, mutu yang baik, aman dikonsumsi, harga yang terjangkau, serta dapat diakses oleh seluruh lapisan masyarakat (Naibaho dan Suhardedi, 2018). Selain itu, tanaman sayur juga mengandung zat-zat non gizi yang juga cukup penting, yaitu serat. Serat dapat membantu mencegah sembelit, mencegah kanker, membantu menurunkan kadar kolesterol, membantu menurunkan berat badan dan lain sebagainya (Esriska dan Muhaijir, 2016).

Seiring peningkatan pengetahuan masyarakat dan kesadaran akan pentingnya menjaga kesehatan, budaya mengkonsumsi sayuran mulai meningkat. Permintaan pangan sayuran yang semakin meningkat menjadikan sektor pertanian sebagai tumpuan hidup seluruh masyarakat (Nurtukubroto, 2006). Peningkatan kebutuhan sayuran harus diiringi oleh ketersedian stok sayuran di pasaran, tidak terkecuali di Ibukota Provinsi Riau yaitu Kota Pekanbaru yang bukan daerah agraris (Esriska dan Muhaijir, 2016). Sehingga suplai sayuran harus di datangkan dari Provinsi tetangga, yaitu Sumatera Barat. Dalam proses suplai sayuran ini tentu akan memakan biaya distribusi yang lebih besar dibandingkan jika sayuran didistribusi dari daerah pinggiran ibu kota. Selain itu, distribusi yang jauh dan waktu yang lama akan menurunkan kualitas sayuran.

Berdasarkan kondisi tersebut, maka urban farming perlu didorong agar kebutuhan sayuran dengan mutu yang baik dan biaya distribusi yang lebih kecil dapat terpenuhi. Daerah pinggiran kota adalah daerah y ang potensial sebagai penyuplai sayur ke Ibukota. Desa Kualu Kec. Tambang Kab. Kampar adalah desa yang berbatasan dengan Kota Pekanbaru, sehingga sangat potensial untuk dikembangkan sebagai desa penyuplai sayuran ke Pekanbaru. Dalam proses produksi sayuran tersebut dapat melibatkan kelompok tani yang terdiri dari ibu rumah tangga dengan pertanian hidroponik.

Budidaya tanaman secara hidroponik merupakan teknologi pertanian modern khususnya tanaman hortikultura. Teknologi ini merupakan salah satu cara budidaya tanaman menggunakan prinsip penyediaan larutan hara sesuai dengan kebutuhan tanaman (Fitmawati et al., 2018). Kegiatan ini disambut antusias oleh masyarakat desa Kualu, namun karena keterbatasan kemampuan finansial petani dalam penyediaan larutan hara dan media tanam, maka pengembangan hidroponik di desa ini terkendala. Salah satu upaya untuk mengatasinya adalah dengan melakukan inovasi teknik hidroponik dari bahan yang murah dan relatif terjangkau seperti dengan memanfaatkan sampah buangan rumah tangga untuk media tanam.

Inovasi dari teknik hidroponik ini adalah Sistem Wick dengan memanfaatkan bahan yang terbuang seperti styrofoam dan botol bekas sebagai wadah penanaman. Sistem Wick merupakan sistem hidroponik yang memanfaatkan sumbu untuk menarik nutrisi. Kelebihan hidroponik Sistem Wick adalah larutan nutrisinya dapat tersirkulasi, volume larutan hara yang dibutuhkan lebih rendah, sirkulasi mencegah lumut, bersih dan mudah dikontrol, tanaman tumbuh dengan optimal, umur panen menjadi lebih singkat dan penggunaan nutrisi yang efisien (Ferrarezi et al., 2016). Untuk meminimalisir biaya produksi dapat diatasi dengan inovasi larutan hara dari sampah buangan rumah tangga menjadi pupuk cair. Sehingga sampah rumah tangga dapat dikelola dan dimanfaatkan dengan baik yang secara tidak langsung turut aktif menjaga lingkungan.

Melalui teknologi hidroponik Sistem Wick ini nantinya dapat mendukung meningkatkan produktivitas sayur-mayur yang bersih dan cukup, aman dikonsumsi, berkualitas, higienis dan dapat diproduksi secara masal untuk memenuhi permintaan pasar sehingga dapat meningkatkan pendapatan masyarakat di Desa Kualu Kec. Tambang Kab. Kampar. Peningkatan produksi akan berorientasi pada peningkatan pendapatan petani dan merupakan sisi lain dari pembangunan ekonomi. Peningkatan ini diharapkan membentuk suatu masyarakat tani yang sejahtera dan mempunyai kelayakan hidup (Syarifuddin, 2016).

\section{Masalah}

Peningkatan kebutuhan sayuran di Ibukota Provinsi Riau yaitu Kota Pekanbaru yang bukan daerah agraris harus diiringi oleh ketersedian stok sayuran di pasaran dengan jumlah yang cukup, mutu yang baik, aman dikonsumsi, harga yang terjangkau, serta dapat diakses oleh seluruh lapisan masyarakat. Selama ini suplai sayuran didatangkan dari Provinsi Sumatra Barat. Dalam proses suplai sayuran ini memerlukan biaya distribusi yang lebih besar dibandingkan jika sayuran didistribusi dari daerah pinggiran ibukota. Selain itu, distribusi yang jauh dan waktu yang lama akan menurunkan kualitas sayuran. Sehingga urban farming perlu didorong 
agar kebutuhan sayuran dengan mutu yang baik dan biaya distribusi yang lebih kecil dapat terpenuhi, melalui pengembangan inovasi pertanian hidroponik di daerah pinggiran kota seperti Desa Kualu Kec. Tambang Kab. Kampar.

\section{METODE PENERAPAN}

\section{Waktu dan tempat}

Kegiatan pengabdian ini dilaksanakan pada hari Minggu, 07 Juli 2019 di Desa Kualu Kec. Tambang Kab. Kampar. Penerapan inovasi teknologi hidroponik melalui pemanfaatan barang bekas dan nutrisi buatan sendiri yang telah disosialisasikan oleh mahasiswa dan dosen Biologi kepada masyarakat terus dilanjutkan sampai masa panen. Pelaksanaan kegiatan pengabdian ini dipersiapkan dan dibantu oleh mahasiswa Kuliah Kerja Nyata (Kukerta) Terintegrasi Universitas Riau tahun 2019.

\section{Metode pelaksanaan}

Metode penerapan kegiatan pembinaan di Desa Kualu Kec. Tambang Kab. Kampar dilakukan dengan beberapa tahapan di antaranya yaitu:

1. Penyuluhan dengan metode tatap muka. Materi disampaikan secara langsung tentang tekonologi hidroponik dan manfaatnya.

2. Diskusi dilakukan melaui partisipasi aktif dan tanya jawab antara tim pelaksana dengan para warga. Kegunaan diskusi adalah untuk mengetahui sejauh mana masyarakat memahami tentang teknologi hidroponik yang telah disampaikan oleh tim pelaksana.

3. Pelatihan dan praktek di lapangan mengenai teknologi hiodroponik.

4. Pembuatan teknologi hidroponik sebagai bahan percobaan pertama oleh tim pelaksana yang bekerjasama dengan warga.

5. Melakukan monitoring dan pendampingan agar teknologi yang disampaikan betul-betul diaplikasikan oleh masyarakat.

6. Dilakukan evaluasi pada bulan berikutnya untuk melihat perkembangan percobaan dan partisipasi masyarakat dalam mengaplikasikan teknologi hidroponik.

7. Indikator keberhasilan yaitu masyarakat sasaran berhasil panen sayur-sayuran yang ditanam dari inovasi teknologi hidroponik melalui pemanfaatan barang bekas dan nutrisi buatan sendiri.

\section{HASIL DAN KETERCAPAIAN SASARAN}

\section{Kondisi Desa}

Desa Kualu Kecamatan Tambang merupakan bagian dari Kabupaten Kampar Provinsi Riau yang memiliki luas wilayah 7000 Km. Berdasarkan dokumen Desa Kualu Kecamatan Tambang Kabupaten Kampar 20102011, desa ini hanya berjarak $19 \mathrm{Km}$ dari ibu kota Provinsi Riau (Lukman, 2011) dan tergolong sebagai dearah pinggiran kota. Berdasarkan Monografi Desa Kualu Tahun 2014, masyarakat Desa Kualu pada umumnya adalah Kuli/ Buruh karena secara keseluruhan masyarakat lebih banyak tidak memiliki pendidikan yang tinggi. Selanjutnya jumlah profesi yang banyak adalah petani karna keadaan penduduk yang memungkinkan untuk bertani dan berkebun. Karet adalah salah satu komoditas perkebunan dari Desa Kualu, namun kondisi perkebunan karet saat ini memiliki produktivitas yang rendah. Sehingga diperlukan anternatif lain yang menunjuang pendapatan masyarakat di Desa Kualu Kec. Tambang Kab. Kampar melalui inovasi teknologi hidroponik guna mendukung ketersedian stok sayuran di ibukota provinsi.

\section{Hidroponik Sistem Wick}

Sistem Wick adalah teknik hidroponik yang paling sederhana dan populer digunakan oleh para pemula. Sistem ini bersifat pasif karena larutan nutrisi mengalir ke dalam media pertumbuhan dari dalam wadah menggunakan bantuan sumbu, sehingga sistem ini akan bekerja maksimal untuk tanaman dan tumbuhan ukuran kecil. Sebaliknya, sistem ini tidak akan bekerja optimal untuk tanaman yang membutuhkan suplai air yang banyak. Tanaman dapat mensuplai air dan nutrisi secara terus-menerus dengan bantuan sumbu tanpa membutuhkan listrik seperti teknologi hidroponik DFT (Deep Flow Technique) yang menggunakan mesin pompa air guna menyediakan airasi yang baik bagi tanaman (Fitmawati et al., 2018). Inovasi hidroponik ini dapat dibuat dengan biaya murah, sehingga dengan biaya minimal masyarakat mampu berkebun hidroponik dan menghasilkan tanaman pangan yang bermutu dan harga terjangkau serta ramah lingkungan. 
Nilai penting dari sistem ini adalah peran aktif petani hidroponik dalam pengelolahan limbah lingkungan sesuai prinsip 3R (Reuse, Reduce, dan Recycle). Bak instalasi untuk menyimpan larutan nutrisi yang mengandung unsur mikro dan makro dapat dibuat dari barang-barang bekas seperti Styrofoam, ember cat, dan baki bekas (Gambar 1). Sumbu dapat dibuat dari kain flanel maupun kain perca dengan daya serap yang baik (Gambar 2). Untuk meletakkan tanaman, net pot dapat dibuat menggunakan gelas plastik air mineral dan botolbotol plastik air mineral. Inovasi larutan hara dapat dibuat dari sampah-sampah rumah tangga yang menghasilkan limbah cair dan difermentasikan menggunakan EM4. Berdasarkan penelitian Sutrisno et al. (2015), nutrisi hasil fermentasi limbah cair tahu menggunakan EM4 mampu mempengaruhi pertumbuhan sawi hijau. Sistem Wick sangat cocok untuk dikembangkan di wilayah perkotaan atau pinggiran kota karena areal pertanian yang dibutuhkan bersifat fleksibel. Instalasi hidroponik bisa ditempatkan pada tempat-tempat tertentu sesuai keinginan. Peletakkan instalasi yang tepat dapat memberikan nilai tambah berupa nilai estetika.

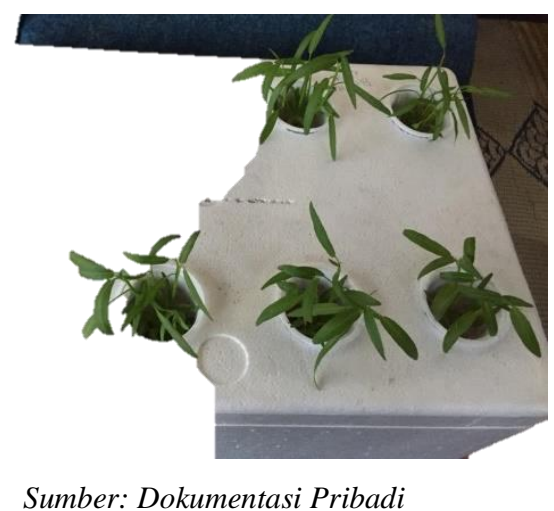

Gambar 1. Instalasi hidroponik Sistem Wick menggunakan styrofoam sebagai bak larutan nutrisi dan sampah gelas plastik sebagai net pot

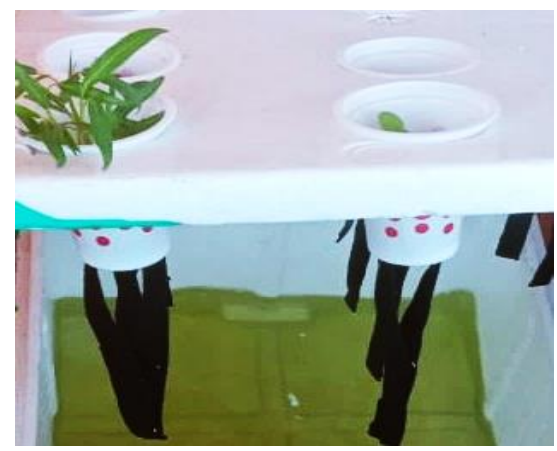

Sumber: Dokumentasi Pribadi

Gambar 2. Sumbu penyerapan larutan nutrisi pada Sistem Wick

\section{Pelatihan dan Pembinaan kepada Masyarakat}

Kebutuhan akan sayuran dengan jumlah yang cukup, mutu terjaga, aman dikonsumsi, dan harga terjangkau di Ibukota Provinsi Riau perlu didukung oleh daerah pinggiran seperti Desa Kualu Kec. Tambang Kab. Kampar. Untuk mendukung pertanian dengan skala produksi secara masal dalam memenuhi permintaan pasar, maka pemanfaatan teknologi pertanian modern seperti hidroponik yang diinovasi sangat diperlukan. Dalam proses produksi ini, pemberdayaan masyarakat daerah pinggiran menjadi hal penting sebagai upaya pembangunan ekonomi daerah melalui peningkatan pendapatan masyarakat. Pelatihan inovasi hidroponik ini melibatkan peran ibu rumah tangga. Kegiatan ini menjadi alternatif bagi ibu rumah tangga untuk mengisi waktu luang agar produktif melalui kegiatan bertani secara modern.

Pada pelatihan ini masyarakat diberi bibit sayuran seperti bayam, pakcoy, dan kankung untuk ditanam pada media tanam rockwool (Gambar 3a). Media tanam yang digunakan bersifat poros, seperti pasir, arang sekam, batu apung, kerikil, rockwool (Anas, 2013). Adapun pertimbangan pemilihan jenis tanaman hortikultura ini 
yaitu kangkung mudah dibudidayakan, berumur pendek, terjangkau, dan kandungan gizi cukup tinggi terutama vitamin A; vitamin C; zat besi; kalsium; potasium; dan fosfor (Sofiari, 2009). Bentuk inovasi yang diterapkan pada pelatihan ini yaitu penggunaan styrofoam sebagai bak instalasi hidroponik, gelas plastik minuman sebagai net pot, dan kain flanel sebagai sumbu yang menyerap larutan nutrisi untuk tanaman kangkung (Gambar 3b). Umumnya nutrisi yang digunakan dalam pertanian hidroponik adalah nutrisi $\mathrm{AB}$ mix yang mengandung zat hara mikro dan makro (Nugraha, 2014), namun permasalahan harga larutan nutrisi yang mahal menjadi kendala bagi masyarakat Desa Kualu.

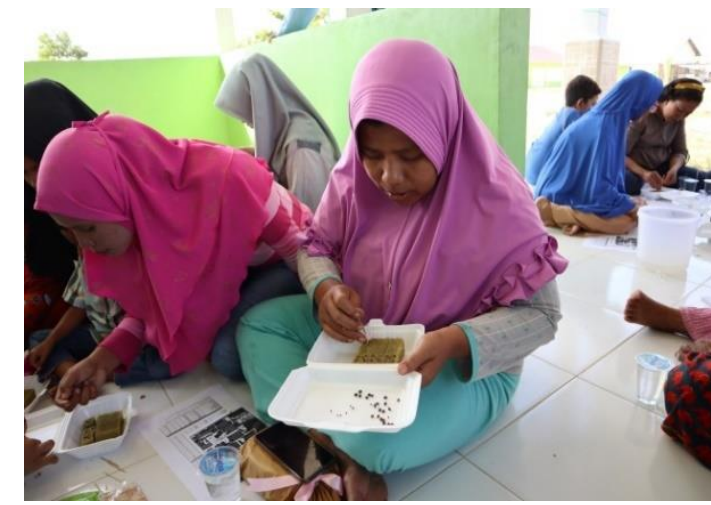

(a)

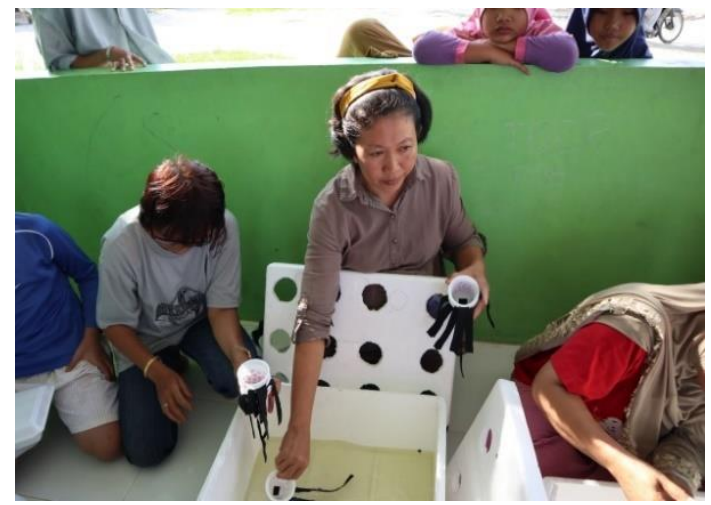

(b)

Gambar 3. (a) Peserta pelatihan melakukan penanaman benih di media tanam rockwol; (b) Pengisian nutrisi ke dalam net pot yang telah diberi sumbu kain flannel.

Untuk meminimalisir biaya produksi diatasi dengan inovasi larutan hara dari sampah buangan rumah tangga menjadi pupuk cair yang terbuat dari kulit buah dan sisa sampah sayuran (Gambar 4a). Sehingga sampah rumah tangga dapat dikelola dan dimanfaatkan sesuai prinsip 3R (Reuse, Reduce, dan Recycle). Selain praktik membuat nutrisi buatan sendiri dari sampah rumah tangga, penyuluh juga memberikan tambahan infomasi sekaligus penggunaan larutan nutrisi yang dijual di pasaran ( $\mathrm{AB}$ mix). Hal ini dilakukan mengingat peserta baru pertama kali melihat praktik pembuatan hidroponik, sehingga membutuhkan banyak informasi tambahan. Hingga tahap akhir pelatihan, masyarakat tetap antusias mempraktikkan peletakan bibit sayuran hasil semai usia seminggu ke dalam instalasi hidroponik (Gambar 4b).

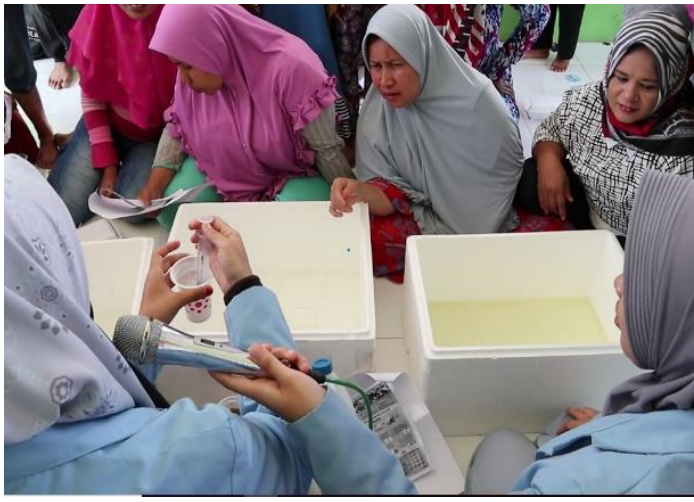

(a)

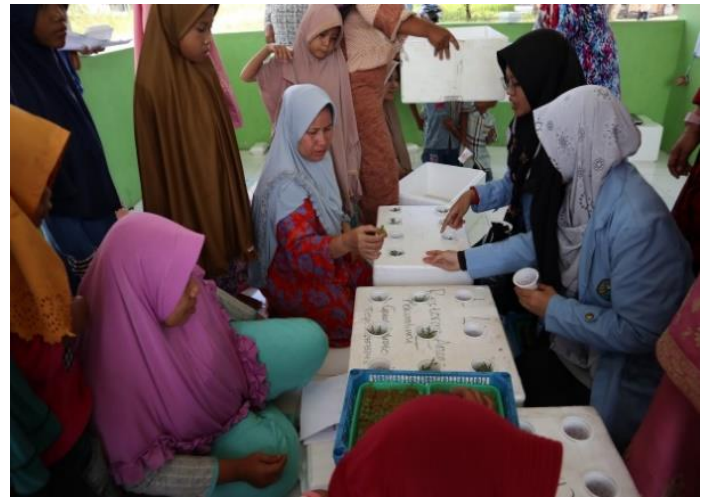

(b)

Gambar 4. (a) Peserta sedang mengikuti proses pembuatan nutrisi buatan sendiri dan penggunaan nutrisi AB mix; (b) Proses peletakan bibit hasil semai usia seminggu ke dalam instalasi hidroponik

Berdasarkan hasil jawaban kuosioner pengabdian masyarakat, menunjukkan bahwa masyarakat Desa Kualu belum mengetahui dan belum pernah mencoba teknologi hidroponik dengan persentase $100 \%$. Seluruh peserta bersemangat untuk mencoba mengaplikasikan metode ini dalam skala rumah tangga yang murah dan ramah lingkungan dengan persentase $100 \%$. Pada saat pelatihan, peserta juga aktif bertanya mengenai aplikasi inovasi teknologi hidroponik Sistem Wick ini (Gambar 5). 


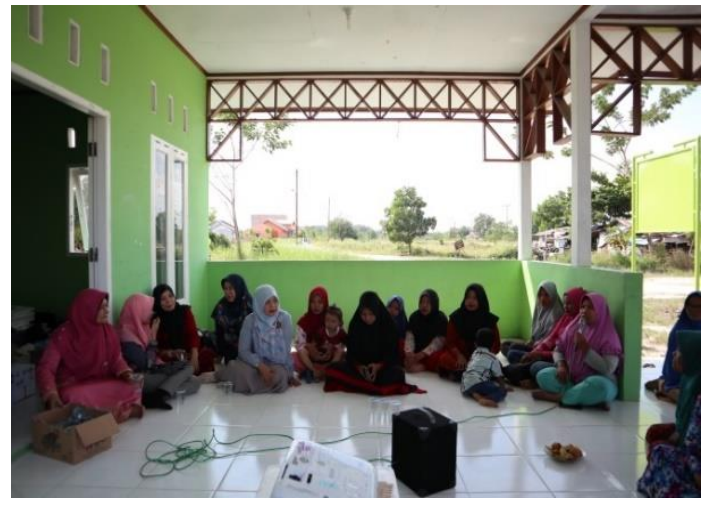

Gambar 5. Peserta antusias bertanya mengenai aplikasi inovasi teknologi hidroponik Sistem Wick kepada penyuluh

\section{Pemeliharaan}

Hidroponik Sistem Wick tergolong teknologi yang mudah untuk diaplikasikan oleh masyarakat umum khususnya ibu rumah tangga, namun pada praktiknya tetap diperlukan pemeliharaan dan pengontrolan yang baik. Pemeliharaan dan pengontrolan tanaman yang telah disemai bersama petani pada kegiatan pelatihan dua minggu sebelumnya, dilakukan oleh mahasiswa Kukerta UNRI periode 2018/2019 (gambar 6). Perawatan dan pemeliharaan ini meliputi pemantauan terhadap kondisi larutan nutrisi di dalam bak penampungan, media, dan sanitasi lingkungan. Petani harus melakukan pengecekan secara berkala agar larutan tidak kering pada instalasi hidroponik. Selain itu, jika ada tanaman yang mati segera dilakukan penyulaman, sehingga tanaman dapat tumbuh seragam.

Pemeliharaan dari hama dan penyakit pada sistem hidroponik ini dilakukan dengan pengendalian hayati tanpa menggunakan pestisida, seperti membersihkan tanaman yang terserang hama dan penyakit. Pengendalian hama ulat dilakukan secara manual dengan cara membuang ulat yang terdapat pada tanaman sayur agar dapat tumbuh optimal hingga masa panen. Pada gambar 6, salah satu tanaman sayuran yaitu kangkung belum dapat dilakukan pemanenan karena ukuran kangkung masih terlalu kecil. Menurut Hidayat (2011), Kangkung siap dipanen 30-45 hari setelah tanam (hst), tergantung dari varietas dan tipe tanaman kangkung.

Setelah dua minggu pemeliharaan dan belum bisa dilakukan pemanenan, masyarakat Desa Kualu tetap merasa puas dan tertarik untuk mengembangakan inovasi teknologi hidroponik Sistem Wick ini dan tidak hanya akan berakhir setelah panen perdana nantinya. Hidroponik dengan inovasi pemanfaatan barang bekas dan sampah rumah tangga ini adalah cara bertani yang baru bagi para ibu rumah tangga di Desa Kualu, sehingga selama proses pelatihan hingga pemeliharaan masyarakat sangat antusias dan tertarik untuk mengaplikasikan teknologi ini di pekarangan rumah.
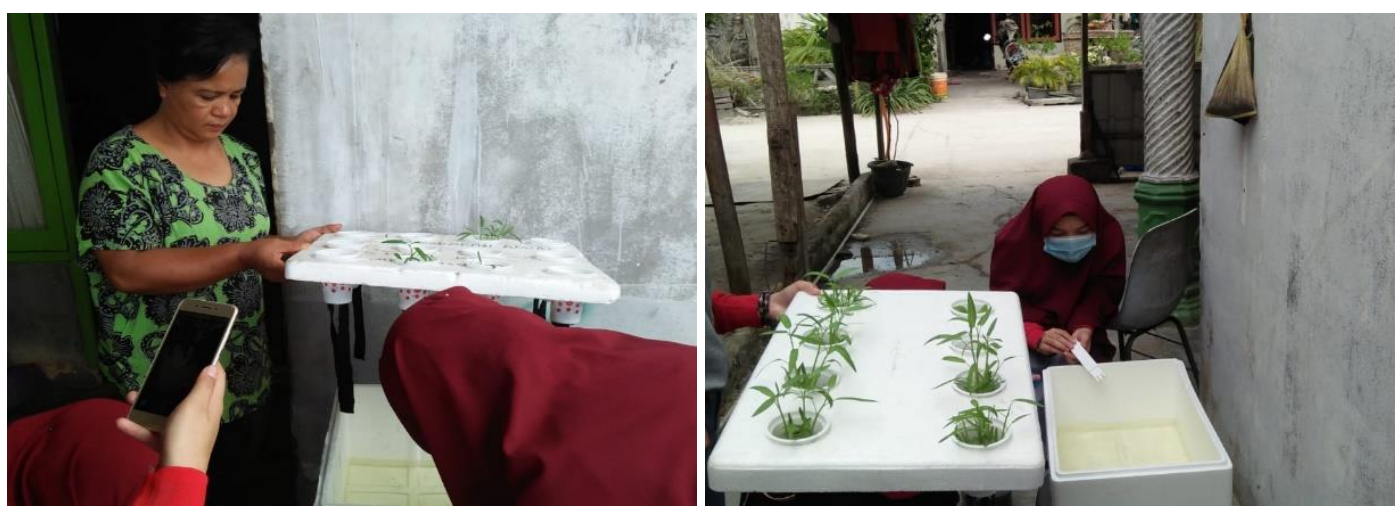

Gambar 6. Pengontrolan pertumbuhan dan nutrisi pada instalasi hidroponik (Kangkung usia dua minggu)

Kegiatan pelatihan dan pembinaan yang dilaksanakan ini menunjukkan pengaruh positif bagi masyarakat. Melalui kegiatan pertanian hidroponik ini, masyarakat Desa Kualu khususnya ibu rumah tangga dapat mengisi aktivitas keseharian dengan kegiatan yang bernilai ekonomi. Kegiatan ini adalah langkah awal dalam rangka 
memaksimalkan potensi daerah pinggiran kota sebagai daerah urban farming. Guna menunjang ketersedian stok sayuran di pasaran ibukota provinsi. Selain itu, kegiatan ini adalah upaya pembangunan ekonomi daerah melalui peningkatan pendapatan masyarakat, sehingga petani di Desa Kualu Kec. Tambang Kab. Kampar tidak hanya bergantung pada sektor perkebunan karet yang produktivitasnya telah menurun saat ini.

\section{KESIMPULAN}

Pelatihan dan pengaplikasiaan inovasi teknologi hidroponik sistem Wick sebagai usaha menunjang ketersedian stok sayuran di pasaran Ibukota Provinsi Riau telah berhasil membuka wawasan petani akan adanya sistem pertanian modern untuk produksi sayur-mayur skala rumah tangga. Selanjutnya berpotensi untuk dikembangkan secara masal dalam memenuhi permintaan pasar, sehingga dapat meningkatkan pendapatan petani di Desa Kualu Kec. Tambang Kab. Kampar. Masyarakat menunjukkan rasa antusiasme yang cukup tinggi dan tertarik untuk mengaplikasian inovasi teknologi pertanian ini di pekarangan rumah secara berkelanjutan. Kegiatan ini adalah langkah awal dalam rangka memaksimalkan potensi daerah pinggiran kota sebagai daerah urban farming.

\section{UCAPAN TERIMA KASIH}

Penulis mengucapkan Terimakasih kepada Lembaga Penelitian dan Pengabdian kepada Masyarakat Universitas Riau skema hibah Pengabdian Kepada Masyarakat Tahun Anggaran 2019 yang telah mendanai dalam pelaksanaan kegiatan pengabdian masyarakat di Desa Kualu Kecamatan Tambang Kabupaten Kampar.

\section{DAFTAR PUSTAKA}

Anas DS. 2013. Teknik Hidroponik. Bogor: Institut Pertanian Bogor.

Esriska, \& M. N. Muhaijir. 2016. Peramalan Produksi Sayuran di Kota Pekanbaru Menggunakan Metode Forcasting. Jurnal Sains Matematika dan Statistika 2(1): 2460-4542 https://doi.org/10.24014/jsms.v2i1.3095

Ferrarezi, R. S., \& R. Testezlaf. 2016. Performance of wick irrigation system using self-compensating troughs eith substrates for lettuce production. Journal of Plant Nutrition 39(1): 50-164.

Fitmawati, Isnaini, S. Fatonah, N. Sofiyanti, \& R. M. Roza. 2018. Penerapan teknologi hidroponik sistem Deep Flow Technique sebagai usaha peningkatan pendapatan petani di Desa Sungai Bawang. Riau Journal of Empowerment 1(1): 23-29 https://doi.org/10.31258/raje.1.1.3

Hidayat, M. 2011. Budidaya dan Produksi Benih Kangkung. http://hortikultura.litbang.deptan.go.id/index.php?bawaan=teknologi/isi_teknologi\&id_men=4\&id_submenu=19 \&id=48 Diakses pada 21 Juli 2019.

Kementerian Kesehatan RI. 2014. Pedoman Gizi Seimbang. Jakarta: Kementerian Kesehatan RI.

Lukman. 2011. Efektivitas Penggunaan Dana Lembaga Ekonomi Desa (LED) Kualu Maju Bersama oleh Masyarakat Miskin Di Desa Kualu Kecamatan Tambang Kabupaten Kampar (Dalam Perspektif Ekonomi Islam). Skripsi Program Sarjana. Universitas Islam Negeri Sultan Syarif Kasim.

Naibaho T. T., \& C. Suhardedi. 2018. Potensi Pengembangan Usahatani Hortikultura Sayuran di Kalimantan Selatan. Artikel Pertanian Balai Besar Pelatihan Pertanian (BBPP). Binuang: Kementerian Pertanian.

Nugraha, R. U., 2014. Sumber Hara Sebagai Pengganti AB mix pada Budidaya Sayuran Daun Secara Hidroponik. Skripsi. Tidak dipublikasikan. Departemen Agronomi dan Holtikultura: Institut Pertanian Bogor.

Nurtukobroto. 2006. Peranan Kontak Tani Dalam Meningkatkan Dinamika Kelompok Tani di Kecamatan Karang Intan Kabupaten Banjar. Fakultas Pertanian: UNLAM.

Sofiari, E. 2009.KarakterisasiKangkung varietas sutera berdasarkan panduan pengujian individual. Buletin Plasma Nutfah 15(2): 49-50.

Sutrisno, A. Evie., R. Herlina, F. 2015. Fermentasi Limbah cair tahu menggunakan EM4 sebagai alternatif nutrisi hidroponik dan aplikasi pada sawi hijau. LenteraBio 4(1): 66-63.

Syarifuddin M. 2016. Analisis Tentang Aktivitas Buruh Tani Dalam Memenuhi Kebutuhan Pokok di Kelurahan Bukuan Kecamatan Palaran Kota Samarinda. eJournal Sosiatri-Sosiologi 4(3): 98-112. 